\title{
Effect of chlorhexidine skin prep and subcuticular skin closure on post-operative infectious morbidity and wound complications following cesarean section
}

\author{
Sara Tikkanen, MD, ${ }^{1}$ Anna Button, BS, MS, ${ }^{2}$ Gideon Zamba, PhD, ${ }^{2}$ Abbey J. \\ Hardy-Fairbanks, $\mathrm{MD}^{1}$
}

Keywords: Cesarean section, infection, wound separation, suture, staples

\section{INTRODUCTION}

Cesarean sections are one of the most commonly performed surgical procedures in the United States and the total cesarean delivery rate continues to increase, reaching an all-time high of $32.9 \%$ in 2009 . $^{1}$ Studies have shown increased adverse maternal and fetal outcomes following a cesarean delivery compared to a vaginal delivery as well as a 3.6 times the risk of death than after a vaginal delivery. ${ }^{2}$ This increased death rate is due to infection, venous thromboembolism and anesthesia complications. In fact, cesarean delivery is the most significant risk factor for postpartum infection. $^{3}$ Other maternal complications following a cesarean section include excessive blood loss, organ damage, and wound complications. ${ }^{4}$
${ }^{1}$ Department of Obstetrics and Gynecology, Carver College of Medicine, University of lowa Hospitals and Clinics, lowa City, IA, 522422

${ }^{2}$ Biostatistics, University of lowa Hospitals and Clinics, lowa City, IA, 52242

Infectious complications have been found to be five times higher in women undergoing a cesarean delivery compared to a normal vaginal delivery. ${ }^{4}$ Both surgical site infections (SSI), which includes both incisional site and non-incisional site infections are increased and on average cost approximately 10 billion dollars in the US annually. ${ }^{5}$ Incisional site infections following a cesarean delivery include both cellulitis as well as an incisional site abscess. Nonincisional site infections, most commonly are endometritis and pelvic abscesses, but also include pelvic thrombophlebitis. Although the range of surgical site infection vary

Please cite this paper as: Tikkanen S, Button A, Zamba G, Hardy-Fairbanks AJ. Effect of chlorhexidine skin prep and subcuticular skin closure on post-operative infectious morbidity and wound complications following cesarean sections. Proc Obstet Gynecol. 2013;3(2):Article 2 [10 p.]. Available from: http://ir.uiowa.edu/pog/. Free full text article.

Corresponding author: Abbey J. Hardy-Fairbanks, Department of Obstetrics and Gynecology, University of lowa, 200 Hawkins Drive, lowa City, IA 42242. abbey-hardy-fairbanks@uiowa.edu

This is an Open Access article distributed under the terms of the Creative Commons Attribution 3.0 Unported License (http://creativecommons.org/licenses/by/3.0), which permits unrestricted use, distribution, and reproduction in any medium, provided the original work is properly cited. 
between studies, the incidence of surgical site infections (SSI) reported by national Healthcare Safety Network in 2008 was between 1.46 and $3.82 \%{ }^{6}$ Other studies have given rates between $2-16 \%{ }^{3}$ Not often included in these studies is the complication of wound separation not associated with infection, however this outcome is a significant clinical outcome. Wound separations due to seroma, hematoma or non-healing wound require significant wound care and prolonged healing by second intent.

Known risk factors for wound complications and other infectious morbidity after cesarean delivery are obesity, increased subcutaneous thickness, premature rupture of membranes, diabetes mellitus, hypertensive disorders, emergency cesarean delivery, twin delivery, ${ }^{7}$ chorioamnionitis, increased surgical blood loss and preeclampsia. ${ }^{8}$

Wound complications are associated with increased cost and decreased patient satisfaction. Many wounds require prolonged packing, depending on the depth, can take months to completely heal. Several interventions have been tried to decrease the risk of wound complications including use of different surgical techniques, perioperative antibiotics, ${ }^{9}$ closing the skin with a subcuticular suture rather than staples ${ }^{10-12}$ and using chlorhexidine-alcohol (CHG-alcohol) skin prep rather than an iodine based prep, ${ }^{11}$ among others.

In response to a quality improvement project to improve the rates postcesarean infectious and wound morbidity two major practice changes were made. These included the universal use of chlorhexidine gluconate-alcohol (CHG-alcohol) abdominal prep and the use of subcuticular suture wound closure. This study evaluated the effectiveness of these two interventions on the infectious and wound complications after cesarean delivery.

\section{METHODS}

University of lowa Hospitals and Clinics (UIHC) is an academic, tertiary care hospital with approximately 1900 deliveries per year. Our cesarean section rate is approximately $30 \%$, consistent with the national average. Due to concern about worsening cesarean infection rates based on clinical experiences, charts of women who had undergone a cesarean delivery during the six month period of July 2010 and December 2010 were reviewed part of a quality improvement project to investigate post-operative infectious morbidity and wound complications Based on infection rates in this cohort two strategic practice changes were made in our institution in an attempt to improve post-operative wound complications and infectious morbidity. These improvements included the nearly universal use of sub-cuticular suture closure of skin. Additionally, surgical skin prep was changed from an iodine based solution to CHG-alcohol. Nursing, OR staff and surgical providers were trained in the use of the new prep.

Institutional review board approval was then sought and granted to 
conduct a retrospective cohort study to investigate if these changes had improved outcomes. Charts of all women having a cesarean delivery in the six month period (April to September 2011) following full implementation of the practice changes were reviewed for postoperative infectious complications and wound separations.

Primary outcomes included wound separation without infection and both deep and superficial surgical site infections (SSI). Center for Disease Control definitions for both types of infection were used to identify these outcomes from patient charts. SSIs can be divided into deep and superficial infections. ${ }^{14}$ Superficial SSIs include those infections which occur within 30 days of operation, involves only the skin and subcutaneous tissue and has either purulent drainage or culture proven organisms along with one clinical marker of infection or an infection is diagnosed by the attending physician. Control group charts were again reviewed during the abstraction of the intervention group charts. Demographic information collected including age, gravity and parity, pre-pregnancy BMI, number of prior cesarean sections, indication for cesarean section. Also the presence of any underlying risk factors known to increase the risk of complications after surgery such as: labor prior to surgery, preterm labor, preterm premature rupture of membranes (PPROM), hypertension, pre-eclampsia, multiple births, diabetes, and chorioamnionitis.

Demographic, risk factor and indication for cesarean data from these two cohorts was analyzed with comparative statistics using t-test and chi-square where appropriate. Outcome data was analyzed first using univariate logistic regression for the use of CHG-alcohol prep, the use of sutures, and the combined effect of the two interventions. Multivariate logistic regression was then used to identify significant risk factors for infections/wound outcomes; and these factors controlled for in a best-fit model. Statistical tests were two-sided and assessed for significance at the $5 \%$ level. Analyses were performed with the SAS 9.3 software package (Cary, $\mathrm{NC}$ ).

\section{RESULTS}

A total of 568 cesarean deliveries were included as part of this study. 300 subjects were delivered by cesarean delivery in the initial six month cohort and 268 subjects in the second six month period after the practice change. $111(37 \%)$ of the early cohort had skin closure with subcuticular sutures (due to surgeon preference) and $0 \%$ used povidone/iodine abdominal prep. In the intervention group 239 (90\%) of patients were closed with sutures and $99 \%$ were treated with CHGalcohol preparation. Four subjects had urgent cesarean deliveries where there was not felt to be adequate drying time for CHGalcohol preparation. Initial statistical comparison of the early versus late cohort showed no demographic differences between the two groups (BMI, age, number of prior cesarean deliveries). However there was a difference between the cohorts in the number of subjects with chronic 
hypertension,

hypertension,

gestational gestational diabetes and gestational diabetes (Table 1). The groups were similar in all other risk factors and indications for cesarean. Outcomes in the early versus late cohort showed decreases in wound infection (12\% to $9 \%)$, but this was not statistically significant $(p=0.32)$. Rates of endometritis were unchanged at $8 \%$ and $9 \%$ respectively. Wound separation decreased significantly from $8 \%$ in the early cohort to $3 \%$ after practice change $(p=0.02)$. Overall postoperative wound complications and infections rates were not significantly different, even when controlling for BMI. Because the interventions were superficial and rates of endometritis would not necessarily be expected to diminish, the overall rate of superficial complications was evaluated (wound infection and separation), but this also was not significantly different after the practice changes.

\section{Table 1}

\begin{tabular}{|l|c|c|c|c|}
\hline Initial results & $\begin{array}{c}\text { Early Cohort } \\
\mathrm{n}=300 \\
(7 / 1-12 / 31 / 10)\end{array}$ & $\begin{array}{c}\text { Late cohort } \\
\mathrm{n}=267 \\
(4 / 19-9 / 7 / 11)\end{array}$ & $\begin{array}{c}\text { OR } \\
(95 \% \mathrm{CI})\end{array}$ & p-value \\
\hline Cesarean deliveries & 300 & 267 & -- & -- \\
\hline Sutures for closure & 111 & 239 & -- & $<.0001$ \\
\hline CHG-alcohol prep & 0 & 263 & -- & $<.0001$ \\
\hline Demographics & & & -- & 0.47 \\
\hline Age (years) & 29.8 & 29.42 & -- & 0.83 \\
\hline $\begin{array}{l}\text { Delivery gestational age } \\
\text { (days) }\end{array}$ & 258.6 & 259.1 & -- & 0.83 \\
\hline BMI & 31.62 & 31.77 & -- & 0.50 \\
\hline Number prior cesarean & $172(57.3 \%)$ & $163(61.0 \%)$ & & \\
\hline & $80(26.7 \%)$ & & -- & 0.02 \\
\hline & & & -- & $<.0001$ \\
\hline Significantly dissimilar risk factors and indications for cesarean & -- & 0.02 \\
\hline Gestational HTN & $0(0.0 \%)$ & $5(1.9 \%)$ & & $<0.0001$ \\
\hline Chronic HTN & $1(0.0 \%)$ & $22(8.3 \%)$ & & 0.004 \\
\hline Pre-Gestational Diabetes & $5(1.7 \%)$ & $14(5.2 \%)$ & & \\
\hline Gestational Diabetes & $1(0.0 \%)$ & $20(7.5 \%)$ & & 0.32 \\
\hline PPROM & $23(2.2 \%)$ & $6(2.2 \%)$ & & \\
\hline Outcomes & & & & \\
\hline Wound infection & $36(12 \%)$ & $25(9 \%)$ & $0.76(0.4-1.30)$ & 0.02 \\
\hline Wound separation & $23(8 \%)$ & $8(3 \%)$ & $0.37(0.16-0.85)$ & 0.73 \\
\hline Endometritis & $16(5 \%)$ & $16(6 \%)$ & $1.14(0.56-2.31)$ & 0.47 \\
\hline $\begin{array}{l}\text { All Post-operative } \\
\text { complications }\end{array}$ & $59(20 \%)$ & $46(17 \%)$ & $0.85(0.56-1.31)$ & \\
\hline All superficial complications & $48(16 \%)$ & $33(12 \%)$ & $0.65(0.51-1.05)$ & 0.07 \\
\hline
\end{tabular}

Statistical modeling of significant

predictors for wound infection, 
wound separation, endometritis and overall complications before and after practice change showed that the best predictors for overall postoperative infectious and wound morbidity was labor prior to cesarean $(p<0.0001$; OR $2.6895 \% \mathrm{Cl} 1.69$ 4.28) and preeclampsia $(p<0.0001$; OR 3.42, 95\%Cl 1.84-6.36). BMI was not a significant predictor $(p=0.1301$; OR $1.0295 \%$ Cl 1.0114.09) of overall complications, endometritis ( $p=0.95$; OR1.00 95\% $\mathrm{Cl}$ 0.96-1.05) or wound separation $(p=0.18$, OR1.03 95\% Cl 0.99-1.07). $\mathrm{BMI}$ was found to be a significant predictor of wound infection alone $(p=0.034$, OR1.03 95\% Cl 1.00$1.07)$, as was preeclampsia $(p=0.022, \quad$ OR2.25 95\% Cl 1.124.50). Having a repeat cesarean as the primary indication was a protective factor for wound infection $(p=0.004$; OR 0.276, 95\% Cl 0.110.67). Predictors for endometritis included labor prior to surgery $(p=0.001$, OR3.64 95\% Cl 11.678.02) and indication for cesarean due to maternal health condition $(p=0.02$, OR3.85 95\% Cl 1.2811.57). Factors found to be predictive of wound separation alone included a history of preterm labor $(p=0.02$, OR7.04 95\% Cl 1.3038.12 ), and cesarean delivery for non-reassuring fetal testing $(p=0.009$, OR2.86 95\% Cl 1.306.32).

Subjects were then further divided women into two groups: the control group, defined as women who had had povidone/iodine prep and skin closure with staples and, the intervention group, defined as those women who had a chlorhexidine skin prep and skin closure with a subcuticular suture. Subjects with other combinations of prep closure (iodine/suture and CHGalcohol/staples) were eliminated from the analysis. This was felt to more accurately represent the primary intervention, and to account for surgeon preference for suture closure in the early cohort.

Comparison of demographic data between these two groups revealed that the two cohorts were similar in all variables aside from the number or prior cesarean deliveries (Table 2a). Control group had more subjects with $\geq 2$ cesarean deliveries. This is likely due to the preferential use of staples in those with repeat cesarean procedures in the control group. The intervention group was noted to have significantly dissimilar amounts of women with gestational diabetes, PPROM, multiple pregnancy and chronic hypertension; all other risk factors were nonsignificant between the groups (Table 2b). Again, this appears to be due to small numbers of these among the cohorts and likely some chart abstraction error. These risk factors were not found to be significant predictors of infection and thus are not likely to have an impact on outcome data as discussed below.

In the control group, 42 subjects had one of the primary complications, accounting for $22.1 \%$ of the control cohort. Intervention group had a lower rate of overall complications with 41 subjects $(17.4 \%)$, but this was not statistically significant $(p=0.22$; OR $0.85,95 \% \mathrm{Cl} 0.56-1.31)$ (Table 2c). Differences in wound 
infection and endometritis, although decreased in the intervention group, did not reach statistical significance. Wound separation without infection occurred in $16(8.4 \%)$ of the control cohort and 7 (3.0\%) of the intervention $(p=0.02$, OR0.33 95\% Cl 0.13-0.83). Thus, there was a significant reduction in wound separation in the intervention group.

\section{Table 2a}

\begin{tabular}{|c|c|c|c|}
\hline $\begin{array}{l}\text { Demographics of } \\
\text { control/intervention groups }\end{array}$ & $\begin{array}{l}\text { Control }(n=190) \\
\text { Iodine/staples }\end{array}$ & $\begin{array}{l}\text { Intervention (n=236) } \\
\text { CHG-alcohol/sutures }\end{array}$ & p-value \\
\hline Age & 29.9 & 29.4 & 0.33 \\
\hline BMI & 32.6 & 31.2 & 0.08 \\
\hline $\begin{array}{l}\text { Gestational age at delivery } \\
\text { (days) }\end{array}$ & 258.8 & 259.8 & 0.72 \\
\hline Prior cesarean deliveries 0 & $100(40.0 \%)$ & $150(60.0 \%)$ & \multirow[t]{3}{*}{0.02} \\
\hline 1 & $51(46.4 \%)$ & $59(53.6 \%)$ & \\
\hline$\geq 2$ & $39(59.1 \%)$ & $27(40.9 \%)$ & \\
\hline $\begin{array}{l}\text { Labor prior to cesarean } \\
\text { delivery }\end{array}$ & $91(47 \%)$ & $93(39 \%)$ & 0.28 \\
\hline
\end{tabular}

\section{Table 2b}

\begin{tabular}{|llll|}
\hline Risk Factors & $\begin{array}{l}\text { Control } \\
\mathbf{n = 1 9 0}(\mathbf{\%})\end{array}$ & $\begin{array}{l}\text { Intervention } \\
\mathbf{n}=\mathbf{2 3 6}(\mathbf{\%})\end{array}$ & P-value \\
\hline PTL & $2(1.0 \%)$ & $6(2.5 \%)$ & 0.3075 \\
\hline Preeclampsia & $20(10.5 \%)$ & $27(11.4 \%)$ & 0.8766 \\
\hline PPROM & $17(8.9 \%)$ & $6(2.5 \%)$ & 0.0045 \\
\hline Multiple pregnancy & $21(11.0 \%)$ & $11(4.7 \%)$ & 0.0158 \\
\hline Gestational HTN & $0(0.0 \%)$ & $5(2.1 \%)$ & 0.0683 \\
\hline Chronic HTN & $1(0.5 \%)$ & $18(7.6 \%)$ & 0.0004 \\
\hline Obesity (BMI 30-40) & $75(39.5 \%)$ & $83(35.2 \%)$ & 0.3659 \\
\hline $\begin{array}{l}\text { Morbid obesity } \\
\text { (BMI>40) }\end{array}$ & $36(18.9 \%)$ & $33(14.2 \%)$ & 0.1866 \\
\hline Chorioamnionitis & $3(0.01 \%)$ & $6(2.5 \%)$ & 0.7370 \\
\hline
\end{tabular}

Statistical modeling of significant predictors for wound infection, wound separation, endometritis and overall complications in the intervention and control group yielded different variables in each outcome (Table $3 a, b$ and $c$ ). Although BMI was not found to be a significant predictor, it was included in multivariate modeling. Having a 
repeat cesarean delivery as the primary indication for surgery was found to be protective from postoperative wound complications, but not endometritis. None of the variables found to be different between two cohorts was a significant predictor of infection. Multivariate analysis controlling for these variables showed did not change in the lack of significant decrease in infectious morbidity.

Table 2c

\begin{tabular}{|llllll|}
\hline Outcome data & $\begin{array}{l}\text { Control } \\
(\mathbf{n = 1 9 0 )}\end{array}$ & $\begin{array}{l}\text { Intervention } \\
(\mathbf{n = 2 3 6 )}\end{array}$ & OR (95\% CI) & P-value \\
\hline Overall Complication Rate & $42(22.1 \%)$ & $41(17.4 \%)$ & $0.85(0.56-1.31)$ & 0.22 \\
\hline Combined superficial complications & $33(17.4 \%)$ & $29(12.3 \%)$ & $0.67(0.39-1.14)$ & 0.14 & 0.28 \\
\hline Wound Infection & $24(12.6 \%)$ & $22(9.3 \%)$ & $0.71(0.35-1.31)$ & $0.33(0.13-0.83)$ & 0.02 \\
\hline Wound Separation & $16(8.4 \%)$ & $7(3 \%)$ & $0.92(0.56-2.32)$ & 0.84 \\
\hline Endometritis & $13(6.8 \%)$ & $15(6.4 \%)$ & & & \\
\hline
\end{tabular}

Table 3a

\begin{tabular}{|lccc|}
\hline \multicolumn{3}{l}{ Predictors of Overall Complications after intervention } & p-value \\
\hline Variable & Odds Ratio & $95 \%$ CI & 0.215 \\
CHG-alcohol/sutures & 0.734 & $0.450-1.196$ & 0.005 \\
Repeat cesarean & 0.395 & $0.207-0.753$ & 0.051 \\
BMI & 1.029 & $1.000-1.059$ & \\
\hline
\end{tabular}

Table 3b

\begin{tabular}{|ll|cc|}
\hline \multicolumn{2}{|l|}{ Predictors of Wound infection after intervention } & \multicolumn{2}{c|}{ p-value } \\
\hline Variable & Odds Ratio & $95 \%$ CI & 0.251 \\
\hline CHG-alcohol/sutures & 0.691 & $0.37-1.30$ & 0.007 \\
Repeat cesarean & 0.230 & $0.08-0.68$ & 0.057 \\
Preeclampsia & 2.145 & $0.98-4.70$ & 0.061 \\
BMI & 1.036 & $0.10-1.07$ & \\
\hline
\end{tabular}

\section{CONCLUSION}

Changes to skin prep and closure procedure did not decrease overall post-operative infectious morbidity significantly. However, we did see 
significant improvement in wound separation rates. There are likely other sources of infection in our institution that need to be improved. Possible other sources include lack of adequate clipping of pubic hair, not prepping with CHG-alcohol inferior enough on the mons pubis due to concern for drying time in hair, lack of vaginal prep and potential negative pressure in the operating room due to increased door openings or changes in personnel.. The limitations of this exploratory study include its retrospective nature as well as our study population size being restricted by the two six month time intervals.

\section{Table 3c}

\begin{tabular}{|lccc|}
\hline \multicolumn{2}{l}{ Predictors of Endometritis after intervention } & & \\
\hline Variable & Odds Ratio & $95 \%$ CI & p-value \\
\hline CHG-alcohol/sutures & 0.894 & $0.41-1.96$ & 0.779 \\
Labor prior to surgery & 3.598 & $1.52-8.52$ & 0.004 \\
$\begin{array}{l}\text { Cesarean due to } \\
\text { maternal health condition }\end{array}$ & 4.160 & $1.32-13.09$ & 0.015 \\
BMI & 1.011 & $0.97-1.06$ & 0.657 \\
\hline
\end{tabular}

\section{Table 3d}

\begin{tabular}{|lccc|}
\hline \multicolumn{2}{|l|}{ Predictors of Wound Separation after intervention } & & \\
\hline Variable & Odds Ratio & $95 \%$ CI & p-value \\
\hline CHG-alcohol/sutures & 0.297 & 0.117 & 0.753 \\
Non-reassuring FHT & 3.949 & 1.598 & 9.758 \\
BMI & 1.021 & 0.971 & 1.074 \\
\hline
\end{tabular}

By analyzing outcomes both as a function of time (before and after practice change) and specifically for patients with the combination of interventions being investigated we can review the impact of implementing a unit practice change in the setting of actual use and showed that outcomes were similar in both types of analysis. BMI was not found to be a significant risk factor for infection in these cohorts despite an average BMI in all groups greater than 30 . Other studies have shown that subcutaneous thickness is more predictive of infection than BMI alone. ${ }^{3}$ Skin thickness was not reviewed in this study. The lack of impact of obesity could also be due to practices among surgeons in this population that differ from those with other BMl's that reduce its impact on wound complications, such as multiple layers of closure, double skin antisepsis, among others. Because the differences in the rates of superficial complications (wound separation and wound infection) 
trended toward significance, it is possible that with a larger sample size a difference in this as well as wound infection alone could have been shown. Endometritis rates between the groups were not significantly dissimilar, which is not surprising from the interventions here, which are primarily superficial. Deep infections likely result more from vaginal contamination than skin.

Cesarean section is a cleancontaminated surgery with a significant risk for infection and thus every labor and delivery unit should be aware of its rates of SSIs and wound complications in an effort to decrease that level as much as possible. Improvement of perioperative infection rate requires a multidisciplinary approach and should include all aspects of infection prevention. We plan to continue to use $\mathrm{CHG}$-alcohol and suture wound closure. Additional efforts on the UIHC units include a review of the negative pressure in the operating theatre, numbers of unnecessary door openings, vaginal preparation and review of instrument sterilization procedure.

\section{References}

1. Martin JA, Hamilton BE, Ventura SJ, Osterman MJ, Kirmeyer S, Mathews TJ, Wilson EC. Births: final data for 2009. Natl Vital Stat Rep. 2011 Nov 3;60(1):1-70. PubMed PMID: 22670489.

http://www.cdc.gov/nchs/data/nvsr/n vsr60/nvsr60_01.pdf. Accessed 2/2013.
2. Deneux-Tharaux C, Carmona $E$, Bouvier-Colle MH, Bréart G. Postpartum maternal mortality and cesarean delivery. Obstet Gynecol. 2006 Sep;108(3 Pt 1):541-8. PubMed PMID: 16946213. http://dx.doi.org/10.1097/01.AOG.00 00233154.62729 .24

3. Vermillion ST, Lamoutte C, Soper DE, Verdeja A. Wound infection after cesarean: effect of subcutaneous tissue thickness. Obstet Gynecol. 2000 Jun;95(6 Pt 1):923-6. PubMed PMID: 10831993. http://dx.doi.org/10.1016/S00297844(99)00642-0

4. Villar J, Carroli G, Zavaleta N, Donner A, Wojdyla D, Faundes A, Velazco A, Bataglia $V$, Langer $A$, Narváez A, Valladares E, Shah A, Campodónico L, Romero M, Reynoso S, de Pádua KS, Giordano D, Kublickas M, Acosta A; World Health Organization 2005 Global Survey on Maternal and Perinatal Health Research Group. Maternal and neonatal individual risks and benefits associated with caesarean delivery: multicentre prospective study. BMJ. 2007 Nov 17;335(7628):1025. Epub 2007 Oct 30. PubMed PMID: 17977819; PubMed Central PMCID: PMC2078636.

http://dx.doi.org/10.1136/bmj.39363. 706956.55

5. Wong ES. Surgical site infections. In: Mayhall CG ed. Hospital epidemiology and infection control. Baltimore: Williams and Wilkins; 1996: 154-75.

6. Edwards JR, Peterson $\mathrm{KD}, \mathrm{Mu} \mathrm{Y}$, Banerjee S, Allen-Bridson K, Morrell G, Dudeck MA, Pollock DA, Horan TC. National Healthcare Safety Network (NHSN) report: data summary for 2006 through 2008, issued December 2009. Am J Infect Control. 2009 Dec;37(10):783-805. doi: $\quad$ 10.1016/j.ajic.2009.10.001. PubMed PMID: 20004811. 
7. Schneid-Kofman N, Sheiner E, Levy A, Holcberg G. Risk factors for wound infection following cesarean deliveries. Int J Gynaecol Obstet. 2005 Jul;90(1):10-5. PubMed PMID: 15913620.

http://dx.doi.org/10.1016/j.ijgo.2005. 03.020

8. Tran TS, Jamulitrat $S$, Chongsuvivatwong V, Geater A. Risk factors for postcesarean surgical site infection. Obstet Gynecol. 2000 Mar;95(3):367-71. PubMed PMID: 10711546. http://dx.doi.org/10.1016/S00297844(99)00540-2

9. Smaill FM, Gyte GM. Antibiotic prophylaxis versus no prophylaxis for preventing infection after cesarean section. Cochrane Database Syst Rev. 2010 Jan 20;(1):CD007482. doi: 10.1002/14651858.CD007482.pub2. PubMed PMID: 20091635.

10. Clay FS, Walsh CA, Walsh SR. Staples vs subcuticular sutures for skin closure at cesarean delivery: a metaanalysis of randomized controlled trials. Am J Obstet Gynecol. 2011 May;204(5):378-83. doi: $\quad$ 10.1016/j.ajog.2010.11.018. Epub 2010 Dec 31. PubMed PMID: 21195384.
11. Darouiche RO, Wall MJ Jr, Itani KM, Otterson MF, Webb AL, Carrick MM, Miller HJ, Awad SS, Crosby CT, Mosier MC, Alsharif A, Berger DH. Chlorhexidine-Alcohol versus Povidone-lodine for Surgical-Site Antisepsis. N Engl J Med. 2010 Jan 7;362(1):18-26.

doi: 10.1056/NEJMoa0810988. PubMed PMID: 20054046.

12. Figueroa D, Jauk VC, Szychowski JM, Garner R, Biggio JR, Andrews WW, Hauth J, Tita AT. Surgical staples compared with subcuticular suture for skin closure after cesarean delivery: a randomized controlled trial. Obstet Gynecol. 2013 Jan;121(1):33-8. doi: http://10.1097/AOG.0b013e31827a0 72c. PubMed PMID: 23262925.

13. Tuuli MG, Rampersad RM, Carbone JF, Stamilio D, Macones GA, Odibo AO. Staples compared with subcuticular suture for skin closure after cesarean delivery: a systematic review and metaanalysis. Obstet Gynecol. 2011 Mar;117(3):682-90. doi: 10.1097/AOG.0b013e31820ad61e.

Review. Erratum in: Obstet Gynecol. 2011 Jun;117(6):1440. PubMed PMID: 21343772.

14. Horan TC, Gaynes RP, Martone WJ, Jarvis WR, Emori TG. CDC definitions of nosocomial surgical site infections, 1992: a modification of CDC definitions of surgical wound infections. Infect Control Hosp Epidemiol. 1992 Oct;13(10):606-8. PubMed PMID: 1334988. http://dx.doi.org/10.1086/646436 